\title{
USO DE PILOTO AUTOMÁTICO NA IMPLANTAÇÃO DE POMARES DE CITROS
}

\author{
TIAGO C. A. OLIVEIRA ${ }^{1}$, JOSÉ P. MOLIN ${ }^{2}$
}

RESUMO: Sistemas de piloto automático vêm sendo utilizados com relativa frequência na agricultura brasileira. Na citricultura, o uso dessa tecnologia vem difundindo-se na operação de abertura de sulcos para o transplantio de mudas. O presente trabalho teve como objetivos avaliar a acurácia de um piloto automático e avaliar possíveis ganhos gerados pela utilização dessa tecnologia de orientação automática em relação ao sistema convencional de abertura de sulcos na implantação de lavoura de citros. A primeira etapa consistiu em georreferenciar as plantas no campo, três meses após o transplantio, com sulcos feitos com as duas tecnologias. Na segunda etapa do trabalho, foi conduzida a avaliação da capacidade operacional da operação de abertura de sulcos, com e sem a utilização de piloto automático coletando dados de tempos e de movimentos com um receptor de GPS. Foi obtido um erro médio de desalinhamento de sulcos de 0,08 $\mathrm{m}$ no sistema convencional e de $0,04 \mathrm{~m}$ com o uso do piloto automático. A operação de abertura de sulcos utilizando o piloto automático apresentou eficiência de campo de 73,4\% e no sistema convencional a eficiência foi de $77,6 \%$. Porém, com piloto automático, foi possível trabalhar com velocidades maiores, o que resultou numa capacidade de campo efetiva maior para este sistema em relação ao sistema convencional de abertura de sulcos $\left(4,65 \mathrm{ha} \mathrm{h}^{-1}\right.$ e 4,09 ha $\left.\mathrm{h}^{-1}\right)$. $\mathrm{O}$ usuário reportou custo da operação de abertura de sulcos menor para o sistema com piloto automático quando comparado com o sistema convencional, especialmente devido à redução de demanda de mão de obra.

PALAVRAS-CHAVE: agricultura de precisão, sistemas guia, GNSS.

\section{USE OF AUTOPILOTS ON CITRUS ORCHARDS ESTABLISHMENT}

\begin{abstract}
Auto-guidance systems have been used with relative frequency in the Brazilian agriculture. On citrus the use of this technology is being applied on the furrows opening for transplanting. The present study aimed to evaluate the accuracy of a RTK auto-guidance system and to compare the field capacity generated by the use of that technology in relation to the conventional system on citrus furrows opening operation. The first stage consisted on georreferencing the plants in the field three months after the transplanting using both technologies for furrows opening. In the second stage field capacities were evaluated by collecting data with a GPS receiver, with the tractor under the two conditions, with and without auto-guidance use. The average aligning error for plants was $0,08 \mathrm{~m}$ in the conventional system and $0,04 \mathrm{~m}$ for the auto-guidance system. Field efficiency for the opening furrows operation was $73,4 \%$ for the auto-guidance system and $77,6 \%$ for the conventional system. However, with the auto-guidance system it was possible to work with higher speeds, what resulted in a larger field capacity $\left(4,65 \mathrm{ha} \mathrm{h}^{-1}\right.$ and 4,07 ha $\left.\mathrm{h}^{-1}\right)$. The user reported operation cost of the opening furrow smaller for the auto-guidance system than for the conventional system, especially due to the labor involved on the conventional system.
\end{abstract}

KEYWORDS: Precision Agriculture, Guidance System, GNSS.

\footnotetext{
${ }^{1}$ Especialista Regional, John Deere, Campinas - SP, oliveiratiagoc@johndeere.com.

${ }^{2}$ Professor Associado, Departamento de Engenharia de Biossistemas, ESALQ/USP, Piracicaba - SP, jpmolin@ usp.br. Recebido pelo Conselho Editorial em: 30-9-2009 


\section{INTRODUÇÃO}

O Brasil é responsável por $53 \%$ da produção mundial de suco de laranja e detém $80 \%$ do comércio internacional desse produto. Em São Paulo, concentram-se aproximadamente 630 mil ha da cultura, o que representa cerca de 79,7\% da produção brasileira (IBGE, 2008).

$\mathrm{O}$ avanço de doenças (CVC e greening) tem sido um desafio para o setor e contribuiu para o crescimento dos investimentos em tecnologia e pesquisa, buscando a redução dos custos de produção agrícola em toda a cadeia produtiva. Um dos exemplos desses investimentos é o crescente avanço de técnicas ligadas à agricultura de precisão na citricultura.

A implantação de um pomar é uma etapa de extrema importância econômica devido ao seu alto custo, uma vez que estão envolvidas diversas operações mecanizadas, que vão desde o preparo do solo até a colocação das mudas nas covas. Após o preparo do solo, é realizado o alinhamento manual das fileiras para o transplantio, etapa que demanda a utilização de uma equipe composta por um profissional de agrimensura e cerca de oito a dez funcionários, que estaqueiam a área para o direcionamento do operador do trator com sulcador para a abertura dos sulcos.

Nos últimos 20 anos, têm sido disponibilizadas tecnologias inovadoras para navegação e posicionamento, graças ao surgimento do GNSS (Global Navigation Satellite Systems), representado pelo seu componente mais ativo, que é o GPS (Global Positioning System). Uma das aplicações agrícolas desses sistemas é no direcionamento de conjuntos mecanizados agrícolas. No Brasil a aviação foi pioneira na utilização de GNSS para aplicações agrícolas, com sistemas de orientação por barra de luzes substituindo os sistemas de orientação visual com bandeiras (MOLIN, 1998). A evolução dessa técnica é representada pelo conceito de piloto automático, que utiliza sinal de GNSS com opções de correção diferencial. Uma delas é o sistema RTK (Real Time Kinematic), em que o sinal de correção é obtido a partir de uma base fixa, que corrige o posicionamento dado pelo sinal dos satélites e repassa ao receptor móvel (trator e outros veículos agrícolas) via comunicação de rádio em ondas UHF, garantindo uma acurácia estática no posicionamento em torno de 0,025 m (BERGTOLD et al., 2009). Na prática, basta o operador criar uma linha de referência definindo o espaçamento entre as passadas, e o software do equipamento replica infinitas passadas à direita e à esquerda da linha de referência. $\mathrm{O}$ posicionamento do veículo é corrigido automaticamente por atuadores no volante ou diretamente no seu rodado. As manobras de cabeceira, no entanto, são feitas manualmente, bastando o operador retomar o controle.

É possível apontar vários fatores responsáveis pela recente adoção dos sistemas de piloto automático. Dentre eles está a diminuição do estresse do operador e, consequentemente, o aumento da capacidade de campo, além do aumento do número de horas trabalhadas, uma vez que é possível aumentar a jornada de trabalho pela facilidade de operação noturna com esse sistema. No Alabama, EUA, HARBUCK et al. (2006) avaliou a acurácia de quatro tipos de sinais de correção diferencial, RTK, SF1, SF2 e WAAS, em um trator equipado com sistema de piloto automático. Para tanto, realizou diversas passadas com o trator, durante vários meses, em diferentes períodos do dia. Com o sistema RTK, obteve um erro médio de aproximadamente $0,10 \mathrm{~m}, 0,40 \mathrm{~m}$ com SF2, 0,34 m com SF1 e 0,24 m com sinal WAAS ao longo dos testes. Outros trabalhos avaliaram sistemas de piloto automático em operações agrícolas (THUILOT, 2002; STOLL \& KUTZBACH, 2000; CORDESSES et al., 2000) utilizando sinal de WASS, RTK, SF1 e SF2 e obtiveram erros médios em relação à linha A-B referência variando de $0,02 \mathrm{~m}$ a $0,10 \mathrm{~m}$.

A citricultura, de forma semelhante a outras culturas perenes, exige alinhamento na disposição das plantas para a otimização do uso da terra e das práticas culturais periódicas. $\mathrm{O}$ uso de esterçamento automático baseado em sinal de GNSS, na implantação de novos pomares, promove a correta disposição das mudas; além disso, oferece recursos para otimizar a operação com potencial redução de custos. Com isso, o objetivo deste trabalho foi avaliar a acurácia da tecnologia de piloto automático RTK na abertura de sulcos e analisar os possíveis ganhos gerados pela sua utilização em relação ao sistema convencional de implantação de pomares de citros. 


\section{MATERIAL E MÉTODOS}

O trabalho foi realizado na fazenda Cambuhy, localizada no município de Matão - SP, e foi dividido em duas etapas. Primeiramente, avaliou-se o paralelismo do transplantio nas operações convencional e com a utilização de trator equipado com piloto automático para a abertura dos sulcos. Posteriormente, realizou-se a avaliação comparativa do rendimento operacional envolvido nos dois sistemas.

A primeira etapa foi realizada em duas áreas cultivadas com laranja, nas quais o processo de transplantio, desde a abertura dos sulcos até a colocação das mudas, foi feito no sistema convencional e com piloto automático, respectivamente. Na Figura 1, é apresentado o organograma das etapas envolvidas nos dois sistemas e observa-se que existe o dobro de etapas envolvidas para a operação convencional em relação ao sistema com piloto automático, em função da necessidade de propiciar condições para o alinhamento feito pelo topógrafo.

$\mathrm{O}$ espaçamento entre as fileiras de plantas foi de $7 \mathrm{~m}$, com espaçamento de $3 \mathrm{~m}$ entre plantas, e as áreas foram sulcadas utilizando-se de um sulcador tracionado por um trator Massey Ferguson, modelo MF $650^{1}$, com $132,3 \mathrm{~kW}$ de potência nominal no motor, equipado com sistema integrado de piloto automático (atuador hidráulico governado eletronicamente) marca Trimble, modelo Autopilot Ag 150. O sinal RTK foi gerado em uma base fixa distante de 100 a $300 \mathrm{~m}$ da área experimental e transmitido sinal via rádio UHF. No tratamento convencional, o sistema de piloto automático estava desativado, e o trator era operado manualmente. Foram individualizadas três parcelas contendo 500 plantas cada e distribuídas em dez fileiras.

\section{Sistema convencional}

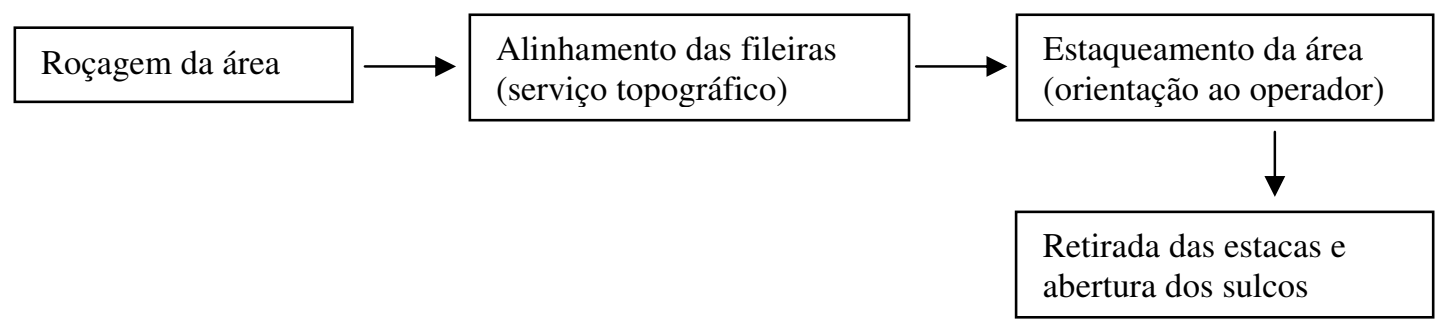

\section{Sistema com auxílio de piloto automático}

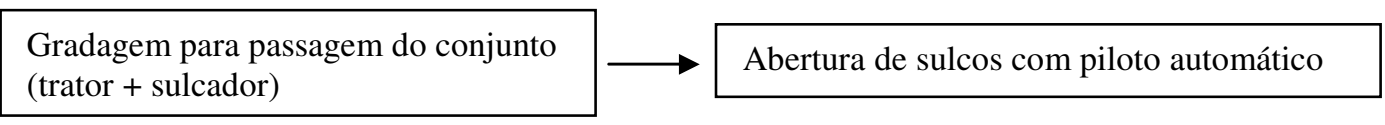

FIGURA 1. Organograma das etapas envolvidas na operação de transplantio em sistema convencional e com a utilização do piloto automático no trator que faz a abertura dos sulcos. Flowchart of the steps involving the transplanting operation on the conventional system and using the autopilot on the tractor that opens the furrows.

Três meses após o transplantio, foram georreferenciadas as plantas utilizando um receptor GNSS RTK Trimble, modelo 5700, de 24 canais, com sinal RTK gerado em uma base fixa localizada na parte mais alta do terreno, a aproximadamente $300 \mathrm{~m}$ do centro do pomar. A antena do receptor foi posicionada manualmente sobre a região central de cada planta, e o ponto coletado foi armazenado em um computador de mão (PDA), utilizando o software TerraSync® (Trimble). A partir das coordenadas de cada planta, foram calculados os erros de espaçamento entre elas. Para os cálculos, utilizou-se uma planilha eletrônica desenvolvida por POVH et al. (2007).

\footnotetext{
${ }^{1}$ A citação de marcas e produtos não implica preferências ou indicações, servindo apenas para o melhor entendimento aos leitores.
} 
A entrada de dados consistiu em fornecer a distância de referência do espaçamento entre fileiras de plantas, equivalente a $7 \mathrm{~m}$, e as coordenadas geográficas das plantas, em graus e decimais, utilizando o datum WGS-84, equivalente ao SIRGAS (IBGE, 2008). As coordenadas geográficas foram transformadas em coordenadas planas UTM (Universal Transversa de Mercator) de acordo com as equações da "Defense Mapping Agency" (DMA, 1989), obtendo-se valores de distâncias em metros e facilitando o cálculo dos erros. Dessa forma, foi possível calcular os espaçamentos entre as passadas do trator e os respectivos erros de desalinhamento que serviram para a análise de comparação entre os tratamentos por meio do teste F de Snedecor, com 5\% de significância.

Na segunda etapa do trabalho, utilizando o mesmo equipamento, conduziu-se a avaliação da capacidade operacional da operação de abertura de sulcos, com e sem a utilização de piloto automático. Na Tabela 1, apresenta-se a descrição do tamanho de cada talhão utilizado no ensaio. Foram selecionados talhões entre 3,4 e 9,2 ha, de acordo com a disponibilidade da fazenda. Cada talhão correspondeu a uma repetição para os respectivos tratamentos (com e sem a utilização de piloto automático).

TABELA 1. Áreas utilizadas no ensaio da avaliação da capacidade operacional, contrastando os tratamentos com e sem o uso do auxílio de piloto automático no trator, para a abertura dos sulcos. Areas used on the field capacity test contrasting the treatments with and without the use of autopilot on the tractor for furrows opening.

\begin{tabular}{lcc}
\hline \multirow{2}{*}{ Operação } & \multicolumn{2}{c}{ Talhão } \\
\cline { 2 - 3 } Com piloto automático & Número & \multicolumn{2}{c}{ Ára) } \\
& 1 & 5,4 \\
Convencional & 2 & 6,7 \\
& 3 & 6,1 \\
& 4 & 3,4 \\
\hline
\end{tabular}

Para a operação em sistema convencional, utilizou-se o trator com o piloto automático desligado. A área foi previamente roçada, e as linhas referentes ao percurso do trator foram demarcadas por um topógrafo, dispondo estacas a cada $30 \mathrm{~m}$. No momento da abertura de sulcos, essas estacas foram retiradas manualmente, repetindo a prática usual da fazenda. Sobre o trator, instalou-se um receptor de GPS marca Garmim, modelo eTrex Legend, que coletou dados constantemente na frequência aproximada de um ponto a cada três segundos. Esses dados foram utilizados para a determinação dos tempos envolvidos ao longo da operação, utilizando procedimento descrito por MOLIN et al. (2006).

Os dados foram processados no sistema de informação geográfica (SIG) SSToolBox (SST Development Group, Stillwater, OK - USA). Obteve-se o tempo total de operação, correspondente ao início e fim de cada repetição, o tempo em que efetivamente o trator esteve sulcando, tempo de manobras de cabeceira e o tempo em que o conjunto, por algum problema técnico ou operacional, foi obrigado a paralisar a operação.

Esse conjunto de informações permitiu a obtenção da capacidade de campo e a eficiência de cada sistema. Foram analisadas as distribuições de frequência das capacidades efetivas em cada tratamento, georreferenciadas dentro dos talhões. Os custos da operação de transplantio utilizando sistema de abertura de sulcos com e sem auxílio de piloto automático, foram obtidos pelo usuário, detalhando as etapas envolvidas. 


\section{RESULTADOS E DISCUSSÃO}

Verificou-se que o erro médio de paralelismo, nas três repetições para o sistema de abertura de sulcos com trator auxiliado por piloto automático, foi de $0,04 \mathrm{~m}$ (Tabela 1), com C.V. de 74,4\%, considerado alto para as condições de campo. Os valores indicam que 68,3\% dos dados apresentam

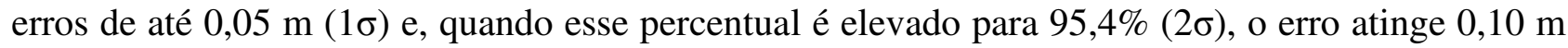
em relação à linha de referência. $\mathrm{N}$

O sistema convencional de abertura de sulcos, o erro médio foi de $0,08 \mathrm{~m}$ para $1 \sigma$ e de $0,19 \mathrm{~m}$ para $2 \sigma$. Observa-se que a média dos desvios-padrão foi menor para o tratamento com piloto automático $(0,03 \mathrm{~m})$ quando comparado à do sistema convencional $(0,06 \mathrm{~m})$, o que indica a capacidade que o piloto automático tem de orientar com maior acurácia o trajeto dos sulcos e a consequente implantação das mudas de forma mais alinhada.

TABELA 2. Erros de alinhamento das plantas em sulcos abertos com o trator auxiliado por piloto automático e sem esse dispositivo, medidos três meses após o transplantio. Errors on the plants parallelism on furrows opened with the tractor equipped with autopilot and without it, measured three months after transplanting.

\begin{tabular}{|c|c|c|c|c|c|c|c|}
\hline \multirow{2}{*}{ Operação } & \multirow{2}{*}{ Repetição } & \multicolumn{4}{|c|}{ Erro (m) } & \multirow{2}{*}{$\begin{array}{l}\text { Desvio-Padrão } \\
\text { (m) }\end{array}$} & \multirow{2}{*}{$\begin{array}{l}\text { C.V } \\
(\%)\end{array}$} \\
\hline & & Médio & $1 \sigma$ & $2 \sigma$ & Máximo & & \\
\hline \multirow{4}{*}{ Com piloto automático } & 1 & 0,04 & 0,06 & 0,10 & 0,17 & 0,03 & 75,8 \\
\hline & 2 & 0,05 & 0,06 & 0,12 & 0,21 & 0,03 & 77,9 \\
\hline & 3 & 0,04 & 0,05 & 0,08 & 0,11 & 0,02 & 69,3 \\
\hline & & $0,04 *$ & 0,05 & 0,10 & 0,16 & 0,03 & \\
\hline \multirow{4}{*}{ Convencional } & 1 & 0,11 & 0,14 & 0,24 & 0,33 & 0,07 & 66,8 \\
\hline & 2 & 0,07 & 0,09 & 0,17 & 0,26 & 0,05 & 75,2 \\
\hline & 3 & 0,06 & 0,07 & 0,15 & 0,27 & 0,05 & 80,8 \\
\hline & & $0,08 *$ & 0,10 & 0,19 & 0,29 & 0,06 & \\
\hline
\end{tabular}

* Siginificativo pelo teste F de Snedecor com nível de 5\%; C.V. - coeficiente de variação.

Houve diferença estatisticamente significativa entre as médias dos erros de alinhamento entre os dois tratamentos, indicando que, na abertura de sulcos feita sem o auxílio de piloto automático, ocorrem desalinhamentos maiores e que podem ser minimizados com a utilização do piloto automático. No entanto, em campo, a diferença é imperceptível, não influenciando na qualidade final do paralelismo de transplantio. Também não é possível afirmar que tal diferença implicaria melhor aproveitamento de área, uma vez que, apesar de significativa, é muito pequena.

$\mathrm{Na}$ Figura 2a, mostra-se que 66\% dos erros de paralelismos entre fileiras de plantas, medidos após três meses do transplantio, para a abertura de sulcos feita com o auxílio de piloto automático, encontram-se à direita da linha de referência (região positiva do gráfico). Sem o auxílio de piloto automático, 51\% dos erros de paralelismo situaram-se à direita da linha de referência, portanto houve uma distribuição mais uniforme dos erros de paralelismo para o tratamento convencional em relação ao sistema com piloto automático.

As linhas de plantas geradas a partir do uso de piloto automático apresentaram acúmulo de erro positivo, à direita da linha de referência. $\mathrm{O}$ sistema de piloto automático não se caracteriza por acumular erros dessa natureza, supondo-se que esse erro seja oriundo de interações entre o trator e o sulcador. 

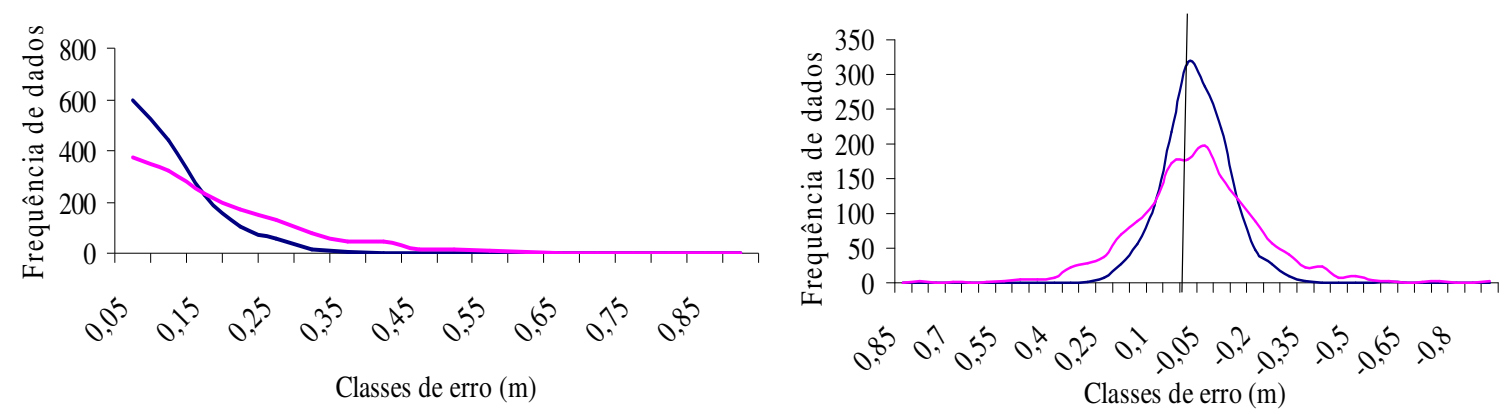

- Piloto Automático — Sistema Convencional

(a)

(b)

FIGURA 2. Frequência acumulada (a) e distribuição de frequência relativa dos erros de paralelismo (b) entre fileiras de plantas, medidos após três meses do transplantio para a abertura de sulcos feita com e sem o auxílio de piloto automático. Frequency distribution (a) and relative frequency distribution of parallelism errors (b) between plants, measured three months after transplanting, for furrows opened with the tractor equipped with autopilot and without it.

Os resultados referentes aos tempos e capacidades para a operação de abertura de sulcos feita com e sem o auxílio de piloto automático são sintetizados na Tabela 3. Segundo o teste F de Snedecor, a diferença entre as médias das velocidades e das capacidades de campo efetivas mostrou-se significativa. Os tempos de manobra e parados para o tratamento com piloto automático foram maiores, o que gerou uma eficiência de campo média menor para os talhões sulcados com piloto automático: $73,4 \%$ contra $77,6 \%$ para os tratamentos em sistema convencional de abertura de sulcos. O tempo de manobra, superior para o piloto automático, é devido à necessidade de o operador ter de alinhar o conjunto antes de entrar na linha de abertura de sulcos, o que não ocorre na operação convencional, onde as estacas do alinhamento orientam o operador na entrada da linha, tornando mais rápida a manobra.

TABELA 3. Síntese dos tempos e capacidades para a operação de abertura de sulcos feita com e sem o auxílio de piloto automático. Synthesis of times and capacities for the opening furrows operation with the tractor equipped with autopilot and without it.

\begin{tabular}{|c|c|c|c|c|c|c|c|c|}
\hline \multirow{3}{*}{ Variáveis } & \multicolumn{4}{|c|}{ Operação com Piloto Automático } & \multicolumn{4}{|c|}{ Operação Convencional } \\
\hline & \multicolumn{8}{|c|}{ Talhão } \\
\hline & 1 & 2 & 3 & Média & 4 & 5 & 6 & Média \\
\hline Tamanhos de áreas (ha) & 9,2 & 5,4 & 6,7 & 7,1 & 6,1 & 3,4 & 3,7 & 4,4 \\
\hline Tempo trabalhando (min) & 141,0 & 58,9 & 88,3 & 96,1 & 93 & 47,0 & 55,1 & 65,0 \\
\hline Tempo parado (min) & 1,5 & 12,6 & 9,5 & 7,9 & 2,4 & 1,2 & 5,0 & 2,9 \\
\hline Tempo de manobra (min) & 42,5 & 23,7 & 34,3 & 33,5 & 21,4 & 16,1 & 16,5 & 18,0 \\
\hline Tempo total (min) & 185,0 & 95,2 & 132,3 & 137,5 & 117,0 & 65,0 & 73,7 & 85,2 \\
\hline Velocidade média $\left(\mathrm{m} \mathrm{s}^{-1}\right)$ & 1,93 & 1,91 & 1,73 & 1,86 & 1,77 & 1,69 & 1,65 & 1,71 \\
\hline $\operatorname{Pr}>\mathrm{F}$ (velocidade) & & & & $<0,001 *$ & & & & \\
\hline Cap. de campo efetiva $\left(\mathrm{ha}^{-1}\right)$ & 3,91 & 5,50 & 4,55 & 4,65 & 3,93 & 4,34 & 4,02 & 4,09 \\
\hline $\operatorname{Pr}>\mathrm{F}$ (cap. de campo efetiva) & $<0,002 *$ & & & & & & & \\
\hline Eficiência de campo & 76,8 & 71,3 & 72,0 & 73,4 & 81,3 & 74,5 & 76,9 & 77,6 \\
\hline
\end{tabular}

* Siginificativo pelo teste $\mathrm{F}$ de Snedecor, com nível de 5\% de probabilidade de erro.

Apesar de os tempos de manobra e tempos parados na operação de abertura de sulcos com piloto automático terem sido maiores do que com o sistema convencional, o sistema que utilizou o 
auxílio do piloto automático permitiu que o conjunto trabalhasse em velocidades superiores às do sistema convencional, diferindo estatisticamente, como mostra o resultado da análise da Tabela 3.

O mesmo é demonstrado pela capacidade efetiva média maior para o tratamento com piloto automático $\left(4,70\right.$ ha $^{-1}$ contra 4,10 ha $\left.^{-1}\right)$, que também difere estatisticamente, segundo o Teste $\mathrm{F}$. Isso resultou em uma economia média de aproximadamente 2 minutos por hectare, resultado próximo ao encontrado por HOLPP (2007) que analisou o uso do sistema de orientação automática em faixas retas na semeadura, para produção de cereais. Os resultados encontrados pelo autor apontaram uma redução de tempo de 3 a 6 minutos por hectare.

Na Figura 3a, são apresentadas as distribuições de frequência das capacidades de campo efetivas (CcE) para os dois sistemas de abertura de sulcos avaliados e, na Figura $3 b$, as frequências acumuladas. Observa-se a capacidade que o trator auxiliado por piloto automático teve de manter a $\mathrm{CcE}$ da operação de abertura de sulcos mais elevada em relação ao sistema convencional. Os agrupamentos estão relacionados às marchas adotadas.

$\mathrm{Na}$ Tabela 4, observa-se que esses valores foram de 4,65 e 4,09 ha $\mathrm{h}^{-1}$, sendo que as velocidades médias foram de $1,86 \mathrm{~m} \mathrm{~s}^{-1}$ para operação com piloto automático e de $1,71 \mathrm{~m} \mathrm{~s}^{-1}$ para sistema convencional, respectivamente. Esse resultado é semelhante aos encontrados por LOWENBERG-DEBOER (1997).

$\mathrm{O}$ autor cita que o piloto automático permite trabalhar em velocidades mais elevadas que em operações sem esse dispositivo, gerando menor sobreposição e maior facilidade de operar o conjunto mecanizado. Observa-se também que, para o sistema de abertura de sulcos com auxílio de piloto automático, ocorreram $12 \%$ de observações com capacidade efetiva nula, enquanto para sistema convencional esse número foi de $2 \%$, o que comprova que houve um número bem maior de paradas durante a operação do sistema com piloto automático. Porém a capacidade que o piloto automático teve em manter as velocidades de trabalho do trator, na abertura dos sulcos, mais elevadas fez com que, na média, este sistema obtivesse valores de capacidades de CcE superiores aos encontrados com o sistema convencional.

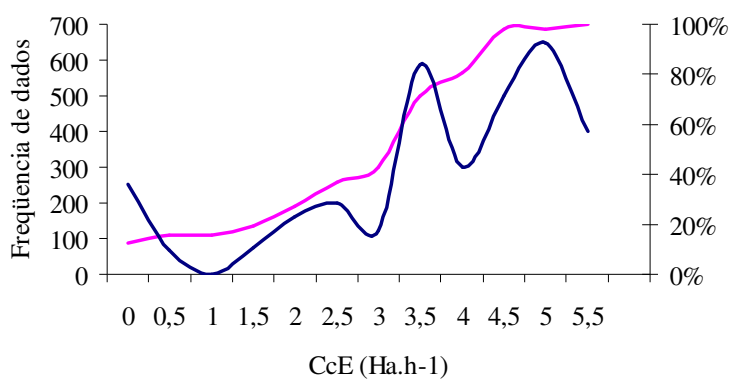

-\% cumulativo — Freqüência

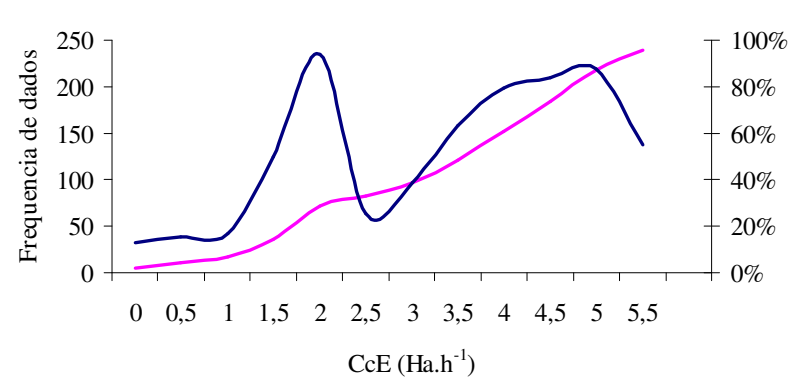

(b)

FIGURA 3. Distribuição de frequência da capacidade de campo efetiva na operação em sistema convencional (a) e com piloto automático (b). Frequency distribution of field capacity for the conventional operation (a) and with the tractor equipped with autopilot (b).

Apesar do maior número de operações que estão envolvidas no sistema convencional de transplantio utilizando sistema de abertura de sulcos (Tabela 5), observa-se que os custos horários entre os dois sistemas são praticamente os mesmos ( $\mathrm{R}$ 140,74 para sistema convencional e $\mathrm{R} \$ 139,94$ com o uso do piloto automático). Isso decorre do custo com o aluguel do equipamento de piloto automático ( $\left.\mathrm{R} \$ 9.500,00 \mathrm{mês}^{-1}\right)$. Todavia, quando os custos horários dos dois sistemas foram divididos pelas respectivas médias de capacidade de campo efetiva da abertura de sulcos, obteve-se 
o custo por hectare, que foi de $\mathrm{R} \$ 34,33$ para sistema convencional e de $\mathrm{R} \$ 29,77$ para o sistema com auxílio de piloto automático, resultando numa economia de $\mathrm{R} \$ 4,56$ por hectare.

TABELA 4. Operações envolvidas, número de funcionários e jornada de trabalho para os dois sistemas avaliados. Operations involved, number of workers and working journey for the two evaluated systems.

\begin{tabular}{|c|c|c|c|}
\hline Sistemas Avaliados & Etapas & $\mathrm{N}^{\circ}$ de Funcionários & Jornada de Trabalho (h) \\
\hline \multirow{5}{*}{ Operação convencional } & Roçada da área a ser sulcada & 1 & \\
\hline & Topografia & 1 & \\
\hline & Estaqueamento & 8 & \\
\hline & Retirada das estacas & 2 & \\
\hline & Abertura de sulcos & 1 & \\
\hline Total & & 13 & 8,8 (um turno) \\
\hline \multirow{2}{*}{ Operação com piloto automático } & Gradagem & 1 & \\
\hline & Abertura de sulcos & 2 & \\
\hline Total & & 3 & 17,6 (dois turnos) \\
\hline
\end{tabular}

TABELA 5. Detalhamento dos custos das operações envolvidas e o custo por unidade de área dos dois sistemas avaliados, com dados fornecidos pela equipe da fazenda. Cost on the operations involved and cost per area on the two evaluated systems, with costs provided by the farm.

\begin{tabular}{|c|c|c|c|c|c|}
\hline Sistemas Avaliados & Etapas & $\begin{array}{c}\text { Capacidade de } \\
\text { Campo Efetiva } \\
\left(\text { ha }^{-1}\right)\end{array}$ & $\begin{array}{c}\text { Jornada de } \\
\text { Trabalho } \\
\text { (h) }\end{array}$ & $\begin{array}{l}\text { Custo } \\
\left(\mathrm{R} \$ \mathrm{~h}^{-1}\right)\end{array}$ & $\left(\mathrm{R} \$ \mathrm{ha}^{-1}\right)$ \\
\hline \multirow{6}{*}{$\begin{array}{l}\text { Operação } \\
\text { convencional }\end{array}$} & Roçada & & & 14,67 & \\
\hline & Topógrafo & & & 6,50 & \\
\hline & Estaqueamento & & & 64,88 & \\
\hline & Retirada das estacas & & & 16,22 & \\
\hline & Abertura de sulcos & & & 38,47 & \\
\hline & Total & 4,1 & 8,8 & 140,74 & 34,33 \\
\hline \multirow{4}{*}{$\begin{array}{l}\text { Operação com piloto } \\
\text { automático }\end{array}$} & Gradagem & & & 38,47 & \\
\hline & Abertura de sulcos & & & 76,94 & \\
\hline & $\begin{array}{l}\text { Aluguel do equipamento } \\
\text { de piloto automático }\end{array}$ & & & 24,53 & \\
\hline & Total & 4,7 & 17,6 & 139,94 & 29,77 \\
\hline
\end{tabular}

Observa-se que os principais ganhos da utilização do piloto automático são decorrentes do aumento da jornada de trabalho e redução de mão de obra envolvida nas etapas da operação. HOLPP (2007) analisou o uso do sistema de orientação automática em sistema de produção de cereais e observou redução no uso de sementes, defensivos e fertilizantes, resultando em potenciais economias da ordem de $€ 6,30$ a 7,30 por hectare ao ano. No presente trabalho, observou-se CcE 6,8\% maior para o sistema com uso de piloto automático em relação ao sistema convencional, com custo operacional, obtido pelo usuário, $7,1 \%$ menor.

\section{CONCLUSÕES}

Avaliou-se a acurácia de um piloto automático RTK na abertura de sulcos e observou-se um erro médio de desalinhamento significativamente maior para o sistema convencional de abertura de sulcos. No caso da cultura de citros, apesar da maior acurácia do piloto automático, somente esse benefício não justifica a adoção desta tecnologia.

Analisaram-se também os possíveis ganhos gerados pela sua utilização em relação ao sistema convencional de implantação de pomares de citros e observou-se que a operação de abertura de sulcos utilizando o piloto automático apresentou eficiência de campo menor. Porém, com piloto automático, foi possível trabalhar com velocidades maiores, o que resultou em capacidade de 
campo efetiva maior para este sistema. A redução de demanda de mão de obra impactou positivamente no custo da operação com piloto automático, obtido pelo usuário.

\section{AGRADECIMENTOS}

À equipe técnica da Fazenda Cambuhy e da empresa Santiago \& Cintra; o trabalho teve apoio do CNPq e da FAPESP.

\section{REFERÊNCIAS}

BERGTOLD, J.S.; RAPER, R.L.; SCHWAB, E.B. The economic benefit of improving the proximity of tillage and planting operations in cotton production with automatic steering. Applied Engineering in Agriculture, St. Joseph, v.25, n.2, p.133-143, 2009.

CORDESSES, L.; CARIOU, C.; BERDUCAT, M. Combine harvester control using Real Time Kinematic GPS. Precision Agriculture, The Netherlands, v.2, p.147-161, 2000.

DEFENCE MAPPING AGENCY. DMA. The universal grids: universal transverse mercator (UTM) and universal polar stereographic (UPS). Fairfax: VA, 1989. 349 p. (Technical Manual, 8358.2).

HARBUCK, T.L.; FULTON, J.P.; MCDONALD, T.P.; BRODBECK, C.J. Evaluation of GPS autoguidance systems over varying time periods. St. Joseph: ASABE, 2006. Disponível em: $<$ http://www.asabe.org>Acesso em: 10 maio 2007. (Meeting Paper, 061042).

HOLPP, M. Work-economics and financial aspects of parallel guidance systems for tractors. In: EUROPEAN CONFERENCE ON PRECISON AGRICULTURE, 16., 2007, Skiathos.

Proceedings... Skiathos: John Stafford, 2007. 6 p.

IBGE. INSTITUTO BRASILEIRO DE GEOGRAFIA E ESTATÍSTICA. Anuário Estatístico do Brasil. Rio de Janeiro, 2008. v. 46.

LOWENBERG-DeBOER, J. GPS based guidance systems for agriculture. SSMC Newsletter, West Lafayette, v.16, dec., 1999. Disponível em: <http://www.purdue.edu/ssmc>. Acesso em: 12 jun. 2007.

MOLIN, J.P. Orientação de aeronave agrícola por DGPS comparada com sistema convencional por bandeiras. Engenharia Agrícola, Jaboticabal, v.18, n.2, p.62-70, 1998.

MOLIN, J.P.; MILAN, M.; NESSRALLAH, M.G.T.; CASTRO, C.N.; GIMENEZ, L.M. Utilização de dados georreferenciados na determinação de parâmetros de desempenho em colheita mecanizada. Engenharia Agrícola, Jaboticabal, v.26, p.759-767, 2006.

POVH, F.P.; SPEKKEN, M.; SALVI, J.V.; MACHADO, T.M.; MOLIN, J.P. Metodologia para análise de paralelismo em sistemas de orientação utilizando planilha eletrônica. In: SIMPÓSIO INTERNACIONAL DE AGRICULTURA DE PRECISÃO, 4., 2007, Viçosa-MG. Anais... Viçosa: Universidade Federal de Viçosa, 2007. 1 CD-ROM.

STOLL, A.; KUTZBACH, H.D. Guidance of a forage harvester with GPS. Precision Agriculture, The Netherlands, v.2, p.281-291, 2000.

THUILOT, B. Automatic guidance of a farm tractor relying on single CP-DGPS. Autonomous Robots, Amsterdam, v.13, p.53-71, 2002. 